\title{
Vitamin A depletion induced by cigarette smoke is associated with an increase in lung cancer-related markers in rats
}

\author{
Yuan Xue ${ }^{1}$, Ethan Harris ${ }^{2}$, Weiqun Wang ${ }^{1}$ and Richard C. Baybutt ${ }^{1,2^{*}}$
}

\begin{abstract}
Background: We have previously demonstrated that cigarette smoke is associated with a significant reduction of retinoic acid in rat lungs and the formation of tracheal precancerous lesions. However, the underlying mechanism of cancer risk induced by vitamin A deficiency is unclear. The purpose of this study was to determine whether the cigarette smoke-induced depletion of vitamin A is related to changes in lung cancer risk-related molecular markers.

Results: We investigated the roles of the retinoic acid receptors (RARs) as well as other biomarkers for potential cancer risk in the lungs of rats exposed to cigarette smoke. Twenty-four male weanling rats were fed a purified diet and divided equally into four groups. Three experimental groups were exposed to increasing doses of cigarette smoke from 20, 40 or 60 commercial cigarettes/day for 5 days/week. After 6 weeks, the retinoic acid concentrations in the lung tissue as measured via high performance liquid chromatography $(H P L C)$ significantly decreased $(P<0.01)$ in cigarette smoke exposed groups. Western Blot analysis revealed that cigarette smoke exposure increased lung protein expression of RAR $a$ in a threshold manner and decreased RAR $\beta$ and RAR $\gamma$ expression in a dose-dependent fashion. Protein expressions of cyclin E and proliferating cell nuclear antigen (PCNA) were increased significantly in a dose-dependent manner in cigarette smoke exposed-groups. Additionally, there was a significant increase in protein expression of cJun and cyclin D1 demonstrating a threshold effect similar to that exhibited by RARa, suggesting a potential independent signaling pathway for RARa in lung carcinogenesis.

Conclusions: Findings from this study suggest that cigarette smoke-induced lung retinoic acid depletion may involve two independent pathways, RARa- and RARß-mediated, responsible for the increased cancer risk associated with cigarette smoke-induced vitamin A deficiency.
\end{abstract}

Keywords: Carcinogenesis, RAR a, RAR $\beta$, cJun, PCNA, Cyclin, Cigarette smoke, Retinoic acid

\section{Background}

Lung cancer mainly caused by cigarette smoking remains the leading cause of cancer death in both men and women in the United States [1]. Understanding the mechanisms of cigarette smoke-induced lung cancer is an important area of research. Very little is known about how micronutrients such as vitamin A play a role in protecting against lung cancer. Two large clinical trials, the $\alpha$-Tocopherol $\beta$-Carotene Cancer Prevention (ATBC) Trials and the $\beta$-Carotene and Retinol Efficiency Trial

\footnotetext{
* Correspondence: Richard.Baybutt@wheaton.edu

'Department of Human Nutrition, Kansas State University, 213 Justin Hall, Manhattan, KS 66506, USA

${ }^{2}$ Department of Applied Health Science, Wheaton College, 501 College
} Avenue, Wheaton, IL 60187, USA
(CARET), found that smokers supplemented with $\beta$ carotene had an increased risk for developing cancer when compared to smokers without $\beta$-carotene supplementation [2]. A research group at Tufts University found that when ferrets, having $\beta$-carotene metabolism similar to humans, were supplemented with $\beta$-carotene and exposed to cigarette smoke, lung concentration of retinoic acid was reduced as was RAR- $\beta$ expression, but cell proliferation markers were elevated [2]. The investigators suggested that the adverse effects upon vitamin A status were largely attributed to the interaction of the high dose of $\beta$-carotene and the cigarette smoke. To our knowledge no one has determined the effect of increased doses of cigarette smoke on lung retinoic acid and lung cancer risk-related molecular markers using a rat model. 
Further research in this area should impove our understanding of the underlying mechanisms for cigarette smoke-induced cancer and may lead to new strategies for decreasing lung cancer risk.

Vitamin A deficiency has been reported to cause preneoplastic changes in tracheal [3] and bronchial epithelium and to be associated with an increased risk of lung cancer $[4,5]$. The loss of retinoic acid receptor beta (RAR $\beta$ ), one of the vitamin A nuclear receptors, is partly responsible for the lung carcinogenesis in vitamin A deficient individuals [6]. Retinoic acid receptor $\beta$ is believed to promote transcription of tumor suppressor genes and has been found to be decreased in many preneoplastic lung cancers $[7,8]$; therefore, decreased expression of RAR $\beta$ has been suggested as a biomarker for lung cancer risk. How cigarette smoke-induced depletion of lung retinoic acid alters RAR $\beta$ in rats is not known.

In contrast to the protective effects of RAR $\beta$, studies have linked increased expression of RAR $\alpha$ with formation of tumors of the breast [9] and cervix [10], potentially by way of an estrogen-mediated pathway [9]. Additionally, vitamin A deficiency is linked with an increased expression of RAR $\alpha$, in contrast with the decreased expression of RAR $\beta$ [11]. The precise mechanism of how RAR $\alpha$ overexpression increases risk of lung cancer-related tumor formation is presently unknown.

Our previous study found that exposure to cigarette smoke decreased vitamin A level in lung tissue and was associated with precancerous lesions in the trachea [3]. To further understand the underlying mechanisms by which vitamin A deficiency might induce lung cancer, eight proteins including retinoic acid receptors, cell cyclins, proliferation markers, and nuclear transcription factors were selected and their nuclear expression was measured by Western blot.

Specifically, we investigated how the vitamin A depletion induced by cigarette smoke is related to decreased expression of RAR $\beta$, a potential cancer risk factor. Since dysregulation of the cell cycle is a prerequisite for the formation of most malignant tumors [12], we further investigated the impact of exposure to cigarette smoke on cell cycle checkpoints. Cyclins are one of the checkpoints in cell cycle, and their abundance is rate-limiting for progression through the different stages of the cell cycle. Another molecular marker for cell proliferation and cancer is nuclear transcription factor activator protein-1 (AP-1). AP-1 is a dimeric transcription factor that consists of homodimers and heterodimers of Jun (c-Jun, JunB, and JunD) and Fos (c-Fos, FosB, Fra1, and Fra2) $[13,14]$ or other transcription factors and proteins. The c-Jun has been found to play an integral role in lung cancer formation [15], yet its precise role in the signaling mechanism and its relation to the RAR pathway(s) remains unclear. Thus, the objective of this study was to determine how cigarette smoke-induced lung retinoic acid depletion altered lung RARs and their relationship to cancer-related cell proliferation markers and cyclin expression. We exposed rats to increasing doses of cigarette smoke for six weeks and then quantified lung retinoic acid and the protein expression of RARs, cell proliferation markers, and cyclins.

\section{Methods}

\section{Animals and treatment}

Male Sprague-Dawley weanling rats (range of weights: 50-75 g, Harlan Sprague Dawley, Indianapolis, IN) were housed individually in stainless steel cages at room temperature, $24{ }^{\circ} \mathrm{C}$, under a 12 -h light:dark cycle (light $0600-1800 \mathrm{~h}$ ) with a relative humidity of $50 \%$. Male rats were chosen because they were previously shown to develop precancerous lesions in response to cigarette smoke-induced vitamin A deficiency. It will be important to evaluate these effects in female rats in future experiments. Animal care and use were approved by the Institutional Animal Care and Use Committee of Kansas State University. Rats were fed a standard AIN-93G diet [16] and water. Food intake was recorded daily and body weight was measured weekly. All groups were pair-fed throughout the entirety of the experiment. The cigarette smoke-treated rats were pair-fed to match the intake of the control group, which was the group that was exposed to air. This was to control for any potential reduced food intake of the cigarette smoke-exposed rats.

\section{Cigarette smoke exposure}

Approximately one month old rats were randomly divided into four groups of six rats per group, and were exposed to air (control), one-pack, two-packs, and threepacks of cigarettes daily (nonfiltered commercial cigarette, 20 cigarettes/pack) for six weeks. The cigarette smoke treatment was modeled after previously published studies [3]. To model cigarette smoke exposure, rats were placed in a plastic chamber that was $65 \mathrm{~cm}$ long, $50 \mathrm{~cm}$ wide, and $45 \mathrm{~cm}$ high with three holes, two for holding two cigarettes at one end of the chamber and another hole on the opposite side of the chamber connected to a tube attached to a Leeson vacuum pump (model \# A6C17EB20.1; Labconco, Kansas City, MO). The rats were exposed to the cigarette smoke of four standard cigarettes for $5 \mathrm{~min}$ followed by $5 \mathrm{~min}$ of air until all the cigarettes assigned to the group were consumed. One pack of cigarettes was considered one session and at least two hours of break were given between sessions. The extent of cigarette smoke exposure was ascertained by measuring total particulate matter inhaled and is noted in our previous study [3]. 


\section{Measurement of level of retinoic acid in lung by high performance liquid chromatography (HPLC)}

Lungs were collected under yellow lights following termination of the study and immediately frozen in liquid nitrogen and kept at $-70{ }^{\circ} \mathrm{C}$ until analysis. The lipid components were extracted from minced tissue, $\sim 200 \mathrm{mg}$ by a standardized method developed by Barua and Olson [17]. Tissue was ground in liquid nitrogen and then transferred to $10 \mathrm{~mL}$ of 2-propanol-dichloromethane (2:1, v/v) plus $0.1 \%$ butylated hydroxytoluene $(1 \mathrm{mg} / \mathrm{mL})$. Twenty $\mu \mathrm{L}$ of retinyl acetate was added as the internal standard to the solution. The mixture was vortexed for $1 \mathrm{~min}$ and then stored under argon at $-20{ }^{\circ} \mathrm{C}$ overnight. The following day, the mixture was vortexed again and returned to freezer. On the third day, the mixture was vortexed, and then filtered through 0.45 um syringe filter. The filtrate was evaporated to dryness under nitrogen. The residue was dissolved in $200 \mu \mathrm{L}$ 2-propanol-dichloromethane $(2: 1, \mathrm{v} / \mathrm{v})$. An aliquot of $50 \mu \mathrm{L}$ was injected onto the HPLC system for analysis according to the procedure by Barua and Olson [17]. The concentration of retinoic acid was determined using the Beckman System Gold software (Beckman Instruments, Fullerton CA) and a $3-\mu \mathrm{m}$ Microsorb-MV column (4.6 x $100 \mathrm{~mm}$ ) (Rainin, Woburn, MA), which was preceded by a guard column of $\mathrm{C}_{18}$. The solvent system consisted of methanolwater $(3: 1, \mathrm{v} / \mathrm{v})$ containing $10 \mathrm{mM}$ ammonium acetate (solvent A) and methanol-dichloromethane $(4: 1, \mathrm{v} / \mathrm{v})$ (solvent B). The flow rate was $0.8 \mathrm{~mL} / \mathrm{min}$. A linear gradient was formed from solvent A to solvent B over a period of $15 \mathrm{~min}$, followed by isocratic elution with solvent B (100\%), for another $15 \mathrm{~min}$. At the end of the run, the gradient was reversed to initial conditions by applying a linear gradient of $5 \mathrm{~min}$. The column was then allowed to equilibrate for 10 min with solvent $\mathrm{A}$ before the next run. Detection was monitored at $340 \mathrm{~nm}$ (Model 166, Beckman Instruments, San Ramon, CA). Under these conditions, all-trans retinoic acid and, alltrans retinyl acetate and all-trans retinyl palmitate was eluted at $\sim 10.5,12.1$ and 15.7 mins, respectively. The recovery rates were $91 \%$ for all-trans retinoic acid, $94 \%$ for all-trans retinyl acetate and $92 \%$ for all-trans retinyl palmitate

\section{Nuclear extraction procedure}

The right lobe of the lung was immediately frozen at the end of the study and the tissue stored at $70{ }^{\circ} \mathrm{C}$ until analysis. In previous studies we used the right lobe of the lung for biochemical analysis and the left lobe for pathological evaluations [3]. The lung tissue nuclei were extracted as follows. Approximately, $0.15 \mathrm{~g}$ (1/3 of the right lobe) was placed in ice cold buffer A $(20 \mathrm{mM}$ Tris/ $\mathrm{HCl} \mathrm{pH} \mathrm{7.8,}$ $1 \mathrm{mM}$ EDTA, $0.1 \mathrm{M} \mathrm{NaCl}, 1 \mathrm{mM}$ phenylmethylsufonyl fluoride, and $1 \mu \mathrm{g} / \mathrm{mL}$ of each of the following: aprotinin, leupeptin and pepstain) and homogenized with a glassteflon homogenizer (Con-Torque Eberbach Company Ann Arbor, MI). The homogenate was then centrifuged at $2000 \times \mathrm{g}$ for $15 \mathrm{~min}$ (Allegra 25R, Beckman Coulter). The supernatant was then removed, and the pellet was re-extracted using buffer $\mathrm{B}$ (buffer $\mathrm{A}$ with $\mathrm{NaCl}$ increased to $0.6 \mathrm{M}$ ) by tearing the pellet and vortexing in order to maximize the nuclear amount in the sample. The solution was then covered with mineral oil and spun at 190,000 $\times \mathrm{g}$ using an ultracentrifuge (Optima L-90 K, Bechman Coulter). The supernatant was then removed by syringe and stored at $-70{ }^{\circ} \mathrm{C}$ until analysis. Protein concentration was quantified using a spectrophotometer (UV-1601PC, Shimadzu).

\section{Western blot}

Approximately $50 \mu \mathrm{g}$ of nuclear extract in Tris lysis buffer was separated on $1.5 \mathrm{~mm} 12 \%$ formaldehyde minigels. Protein concentration was measured by the Bio-Rad protein assay (Bio-Rad, Hercules, CA). The sample volumes were calculated to produce equal protein content. The protein was then transferred to a nitrocellulose membrane (Bio Rad, Hercules, CA) using TrisGlysine Buffer $\mathrm{pH} 8.3$ and blocked one hour at room temperature in a $5 \%$ dry milk PBS solution. Antibodies against retinoic acid receptors $\alpha, \beta, \gamma$, cyclin D1 and E, proliferating cell nuclear antigen (PCNA), and c-Jun and c-Fos were purchased from Santa Cruz Biotechnology (Santa Cruz, CA). An antibody against $\beta$ actin was used for loading control (data are not provided in this paper). Antibodies after dilution recommended by the manufacturer were incubated overnight at $4{ }^{\circ} \mathrm{C}$. The blots were washed and then incubated with secondary antibody (1:1000, Santa Cruz, CA). The blots were visualized using Chemi Glow West (Alpha Innotech Corporation) on a Fluorochem 8800 (Alpha Innotech Corporation) imaging system. The degree of expression of immunodetected signaling molecules was measured by densitometry.

\section{Statistical analysis}

All data are presented as means \pm SEM. Treatment effects were analyzed using one-way ANOVA with the general linear model procedure (SAS Institute, Cary, NC). In all analyses, $P<0.05$ was considered significant. The correlation coefficients of each pair of groups are calculated in SAS PROC CORR.

\section{Results}

Concentrations of retinoic acid were decreased in lungs exposed to cigarette smoke

All animals completed the cigarette smoke exposure treatment. The concentration of retinoic acid in lungs was decreased when exposed to 2-pack and 3-pack of cigarettes smoke $(P<0.021$, Fig. 1$)$, but not significantly 


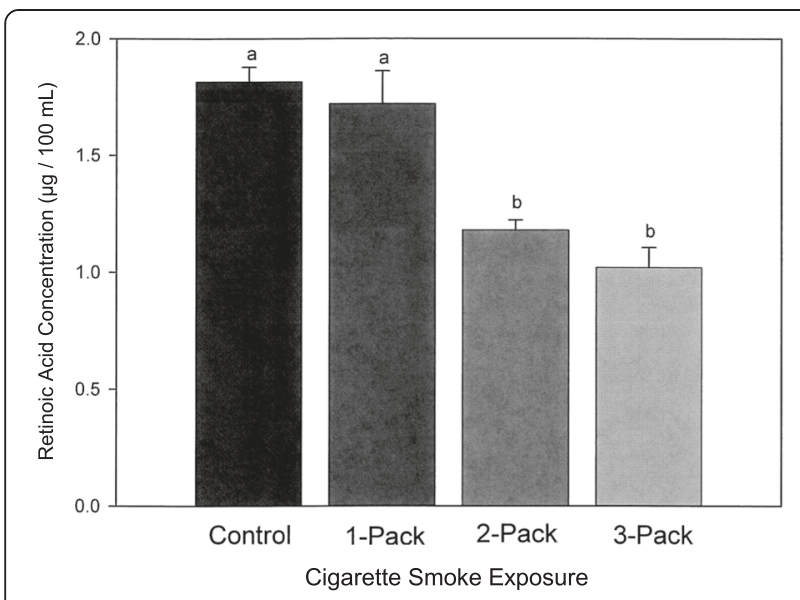

Fig. 1 Retinoic Acid Level in Lungs Exposed to Cigarette Smoke. The all-trans retinoic acid level in lungs exposed to different doses of cigarette smoke for 6 weeks. Values are mean $\pm S E M, n=6$. Groups with different letters are significantly different, $P<0.05$

different for the treatment group exposed to one pack of cigarettes when compared to the control group.

\section{Expressions of RAR $\beta$ and RAR $\gamma$ were decreased in lungs exposed to cigarette smoke}

The expression of RAR $\beta$ was significantly reduced by more than $50 \%$ in the group that was exposed to one pack of cigarettes and undetectable in the other two cigarette smoke-treated groups using Western blot analysis. A representative sample of RAR $\beta$ protein expression is depicted in Fig. 2. High doses of cigarette smoking exposure $(2$ and 3 packs) significantly $(P<0.05)$ decreased RAR $\gamma$ expression.

\section{Expression of RARa was increased in lungs exposed to a three pack dose of cigarette smoke}

The expression of RAR $\alpha$ was significantly increased in the group that was exposed to three packs of cigarettes using Western blot analysis $(P<0.038)$. A representative sample of RAR $\alpha$ protein expression is depicted in Fig. 2. There appears to be a dose threshold for the RAR $\alpha$ lung response when exposed to increasing amounts of cigarette smoke.

\section{Expressions of proliferation indicators: PCNA and cJun were increased}

A strong proliferative response in lungs either indicated by PCNA or by cJun was observed in cigarette smoketreated groups. The expression of cJun significantly increased only in the treatment group that was exposed to 3-pack of cigarette smoke (Fig. 2, $P<0.001$ ). There was a dose-dependent response found between cigarette smoke exposure and PNCA. The expression of PCNA
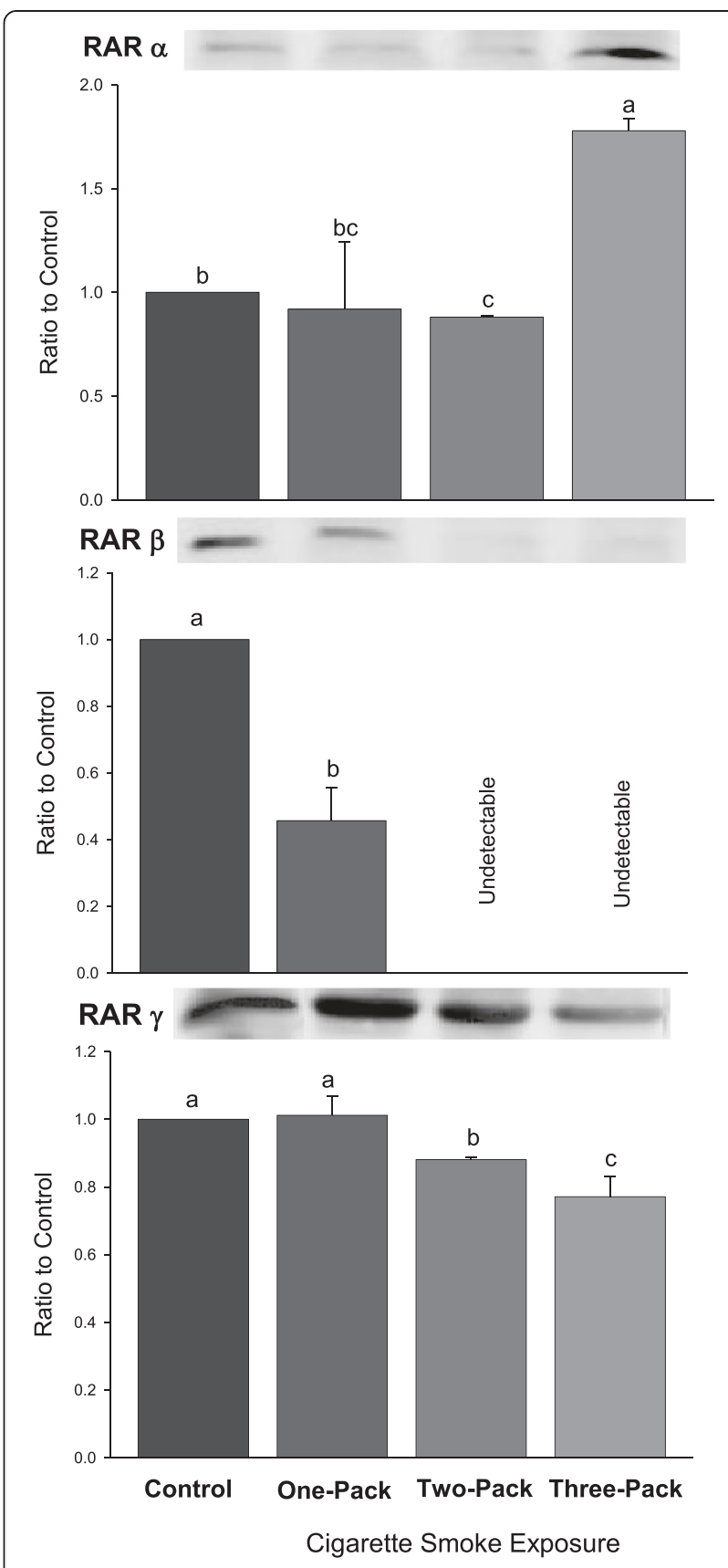

Fig. 2 Western Blot Analysis for RAR Levels. Protein expressions of retinoic acid receptors (RARs: RARa, $\beta, \gamma$ ) in lungs exposed to different doses of cigarette smoke for 6 weeks. Representative Western Blot analyses are shown that used anti-RARa, anti-RAR $\beta$ and anti-RARy antibodies. The size of the detected RARa, RAR $\beta$ and RARy were all 53 kilodaltons $(\mathrm{kDa})$. The intensity of the protein signal was determined by densitometry analysis (three samples in each group). The relative protein values in the three treatment groups were calculated as a mean value \pm standard deviation (SD) of the data relative (ratio) to control with the control set at 1.0. Different letters represent significant difference among groups $(P<0.05)$ 
was increased when the dose of cigarette smoke exposure was increased $(P<0.001)$.

\section{Cyclins E and D1 were increased in lungs exposed to cigarette smoke}

Two G1 phase cyclins were investigated in this study. Cyclin E was found to be significantly increased in all three treatment groups (Fig. 3, $P<0.05$ ), exhibiting a dose-dependent response. However, for cyclin D1, there was no dose-dependent response, and only the group exposed to the highest dose of cigarette smoke had significantly increased expression compared to the control group and other two groups.

\section{Linear correlation coefficients between levels of gene expression among different groups}

The protein level of RAR $\beta$ in rat lung was significantly decreased and directly correlated with the concentration of retinoic acid $(P<0.001)$ in response to increasing exposure to cigarette smoke. The responses of RAR $\beta$ and retinoic acid to the increased cigarette smoke exposure were inversely related to the level of cyclin $\mathrm{E}(P<0.001)$ and PCNA $(P<0.05)$, but not significantly associated with the expression of cyclin D1 or cJun (Table 1). Cyclin D1 was significantly correlated with cJun $(P<0.001)$ and with PCNA $(P<0.05)$. The cigarette smoke response curve for RAR $\alpha$ was similar to that of cyclin D1 and cJun (Figs. 2, 3, and 4). There was no significant increase
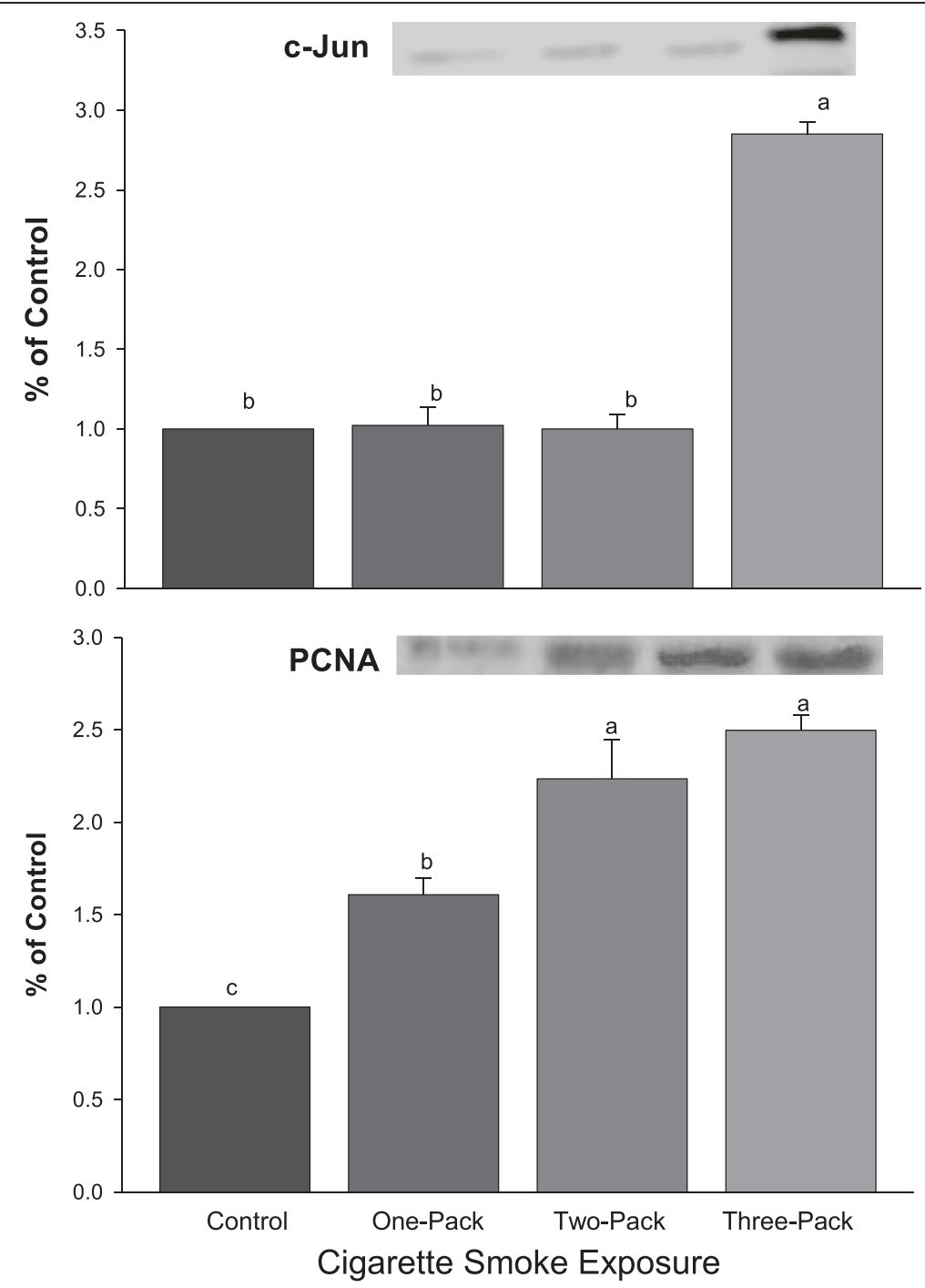

Fig. 3 Western Blot Analysis for cJun and PCNA. Protein expressions of cJun and PCNA in lungs exposed to different doses of cigarette smoke for 6 weeks. Representative Western Blot analyses are shown that used anti-cJun, and anti-PCNA antibodies. The size of the detected cJun and PCNA were $39 \mathrm{kDa}$ and $36 \mathrm{kDa}$, respectively. The intensity of the protein signal was determined by densitometry analysis (three samples in each group). The relative protein values in the three treatment groups were calculated as a mean value \pm standard deviation (SD) of the data relative (ratio) to control with the control set at 1.0. Different letters represent significant difference among groups $(P<0.05)$ 
Table 1 Correlation Coefficients

\begin{tabular}{lllllll}
\hline \multicolumn{6}{l}{ Correlation for Retinoic Acid and Lung Cancer-Related Markers } \\
\hline Measurements & RAR $\beta$ & cJun & PCNA & cyclinD1 & cyclinE & RA \\
\hline RARß & 1.00 & - & - & - & - & - \\
CJun & -0.53 & 1.00 & - & - & - & - \\
PCNA & $-0.89^{*}$ & $0.81^{*}$ & 1.00 & - & - & - \\
cyclinD1 & -0.50 & $0.98^{* *}$ & $0.80^{*}$ & 1.00 & - & - \\
cyclinE & $-0.98^{* *}$ & 0.56 & $0.90^{*}$ & 0.54 & 1.00 & - \\
RA & $0.96^{* *}$ & -0.53 & $-0.84^{*}$ & -0.50 & $-0.95^{* *}$ & 1.00
\end{tabular}

Linear correlation coefficients between levels of protein expression in the different groups. This table shows the linear correlations between levels of protein expressions and retinoic acid concentration among different groups. Correlation coefficients are designated by a star * and two star ** to indicate significance of $P<0.05$ and $P<0.001$, respectively. All other correlations were not significant

$R A$ retinoic acid, $R A R$ retinoic acid receptor, $P C N A$ proliferating cellular nuclear antigen

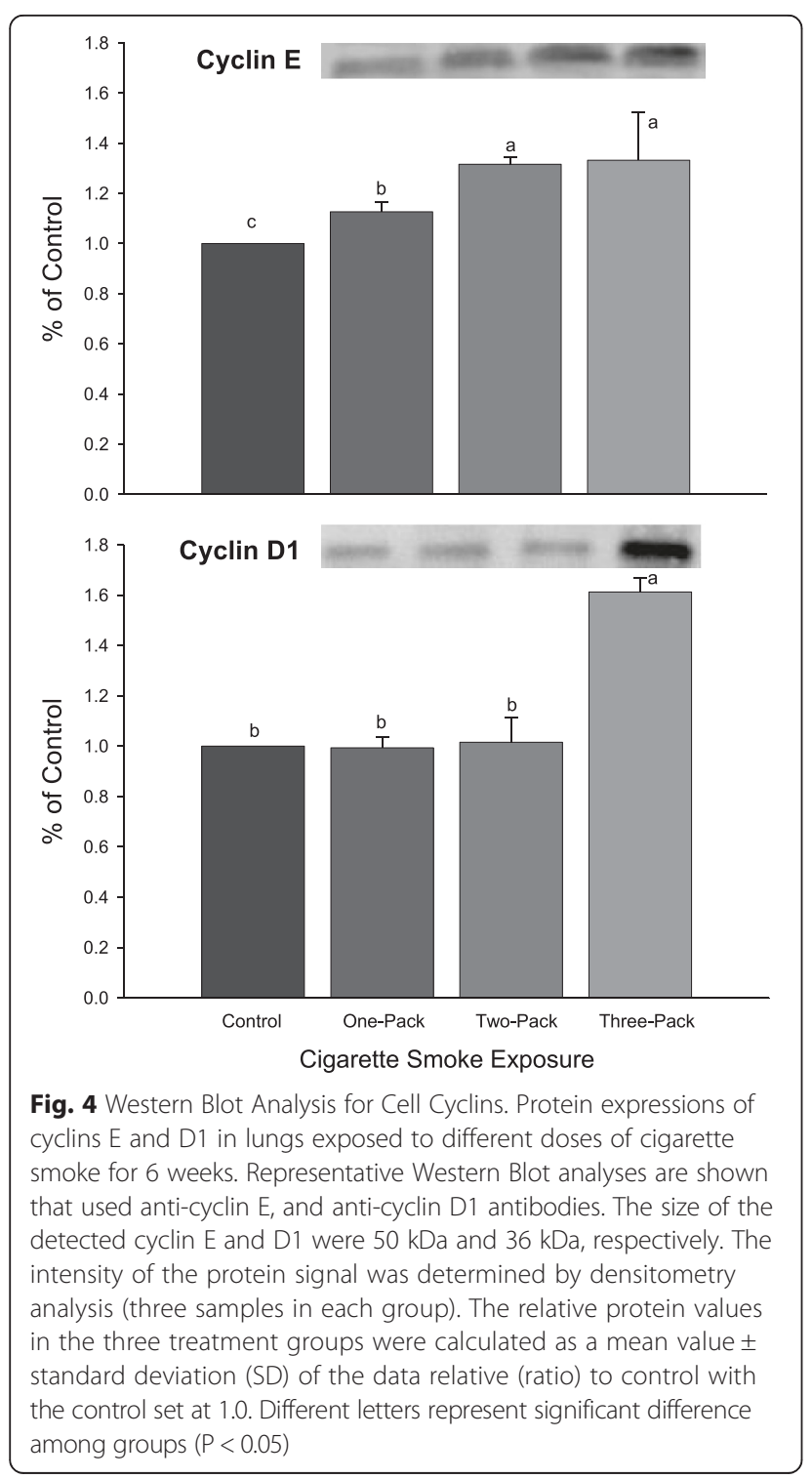

in RAR $\alpha$, cyclin D1, or cJun at the lower dose of cigarette smoke (one or two packs/d), but a significant increase in all three at the highest dose of cigarette smoke (three packs).

\section{Discussion}

In this study, we investigated how increasing exposure to cigarette smoke depleted retinoic acid in rat lung tissue and how this depletion was associated with increased lung cancer risk via changes in protein levels of specific biomarkers for cell proliferation and cell cycle transition. It is well-known that cigarette smoke contains numerous radicals that may deplete vitamin $\mathrm{A}$, including both carbon-centered and oxygen-centered products from $\mathrm{NO} / \mathrm{NO}_{2}$ reactions with reactive compounds such as isoprene in smoke. In addition, benzopyrene, a carcinogen in cigarette smoke, has been found to deplete lung and liver vitamin A levels when rats are fed benzopyrene [18]. We found that cigarette smoke exposure decreased both the lung retinoic acid concentration and the protein levels of RAR $\beta$ in a dose-dependent manner while increasing expression of RAR $\alpha$ in a thresholddependent response. Expression of two cell proliferation markers, cJun and PCNA, increased. In addition, the expression of two $G_{1}$ phase cyclins, D1 and E, were increased in response to cigarette smoke exposure.

This study presents the first evidence that six-week exposure to one, two, and three packs of cigarettes per day, five days per week, depletes lung retinoic acid in rats and is associated with increasing molecular markers for cancer while depleting the tumor suppressor RAR $\beta$. In a previous study, we exposed rats to two packs of cigarettes per day for four weeks and used microarray analysis to discover that dietary retinoic acid downregulated genes that promoted cell divisions/proliferation in response to cigarette smoke [19]. Additionally, we have shown that two-pack cigarette exposure per day over six weeks depleted lung retinol and was associated with precancerous tracheal lesions and emphysema [3]. Cigarette smoke-induced depletion of lung retinoic acid has been reported in ferrets [8]. In addition, airborne particulate matter which contains pentachlorophenol, also in cigarette smoke, depleted lung vitamin A [20] as did benzopyrene the cigarette smoke carcinogen [18].

\section{Role of RAR $\beta$ in lung cancer}

RAR $\beta$ expression was decreased in one-pack of cigarette smoke exposure and undetectable in two-pack and threepack doses. Because many studies suggest a tumor suppressor role for RAR $\beta$ [21] and reduced RAR $\beta$ expression is found in about $45-50 \%$ of lung cancers $[22,23]$, the decreased expression of RAR $\beta$ observed in this study suggests a greater risk for development and/or promotion of lung cancer. The reduction in RAR $\beta$ expression may be 
caused by genomic loss or epigenetic silencing due to genomic methylation or histone deacetylation [24-26]. Hypermethylation of the RAR $\beta$ promoter region is an early event in lung carcinogenesis and is one of the most frequent methylation defects detected in the histopathologically normal bronchial epithelium of heavy smokers [27]. Thus, the loss of RAR $\beta$ expression may be an early event leading to lung carcinogenesis [22, 28].

The concentration of retinoic acid was decreased significantly in the cigarette smoke-exposed groups which strongly correlated with the decreased expression of RAR $\beta$. The decreased retinoic acid likely preceded the loss of RAR $\beta$ expression since others have found that all-trans-retinoic acid is a potent inducer for mRNA for RAR $\beta$ [29]. We previously found that the depletion of vitamin $\mathrm{A}$ is associated with precancerous lesions in cigarette smoke-exposed trachea [3]. It has long been known that retinoic acid has a cancer-preventative effect because vitamin A-deficient rodents develop squamous metaplasia, a precancerous lesion [30]. More recently, it has been discovered that lung RAR $\beta$ levels return to normal if rats that were previously fed a vitamin Adeficient diet were supplemented with retinoic acid [11]. As previously mentioned, we have found that dietary retinoic acid can reverse some of the increased lung cancer-related gene expression in response to cigarette smoke in rats [19]. The role of vitamin A in protection against cigarette smoke-induced cancer is an important area for further research.

Because RAR $\beta$ acts as a tumor suppressor gene, its reduced expression could lead to enhanced cell proliferation and potentially to tumor formation. It has previously been shown that an antagonist to RAR $\beta$ can abolish the retinoic acid inhibition of mitogenic pathways, extracellular signal regulated kinase (ERK 1/2), and cJun N-terminal kinase (JNK) in human scleral fibroblasts [31]. In the present study, a dose dependent increase in the level of a marker of cell proliferation, proliferating cell nuclear antigen (PCNA), in cigarette smoke-exposed groups was observed. Expression of one of the AP-1 proteins, cJun, also was increased and strongly correlated with the expression of PCNA. Overexpression of AP-1 is found to be associated with squamous metaplasia and with increased expression of PCNA in the lung [8]. Mechanistically, the RAR $\beta$ DNA binding domain was important for inhibition of AP-1 activity [32]. In addition, it is found that RAR $\beta$ has unique anti-AP-1 activity in that it exhibits strong inhibition of AP-1 activity via protein-protein interaction in the absence of the ligand retinoic acid [33, 34]. It is interesting to note that in the present study the increased RAR $\alpha$ response closely resembles the increased cJun response to the smoke exposure, whereas there did not appear to be a significant inverse relationship between
RAR $\beta$ and cJun suggesting independent responses for RAR $\alpha$ and RAR $\beta$ to the cigarette smoke.

\section{Role of RARa in Lung Cancer}

Decreases in retinoic acid increase AP-1 transcriptional activity [34] and thereby increases the expression of cJun genes. Retinoic acid is also found to down-regulate the transcriptional activity by cJun in bacteria [35]. Findings of the present study suggest that an increase cJunmediated AP-1 transcriptional activity observed in retinoic acid-deficient, cigarette smoke-exposed rat lungs can be more attributed to an agonistic mechanism via RAR $\alpha$ over-expression than reduction in RAR $\beta$-mediated antagonistic response. cJun levels measured in rat lungs closely replicated the threshold-response demonstrated by RAR $\alpha$ expression in response to the cigarette smoke exposure. No significant increases were observed until the dose of cigarette smoke exposure reached 3 packs/d. This apparent parallel response suggests a cooperative interaction of RAR $\alpha$ and AP-1 as reported previously using T47D breast cancer cells [36].

\section{Role of cell cyclin irregularity in lung cancer}

Next, we investigated cyclins involved in promoting $G_{1}$ phase to $\mathrm{S}$ phase transition to observe changes in factors related to cell cycle regulation. In the majority of cells/ tissues that have been examined, cell cycle regulation occurs in the $G_{1}$ phase. Moreover, the connection between cyclins and cancer has been substantiated with $G_{1}$-type cyclins since $G_{1}$ phase to $S$ phase progression is a key factor in carcinogenesis [12].

\section{Cyclin $E$}

Cylin E regulates late G1 and early S phases [37]. Cyclin $\mathrm{E}$, forming complexes with cyclin-dependent kinase 2, is essential for G1/S transition and has a profound role in oncogenesis. Both cyclin E and D1 were overexpressed in the lung exposed to heavy cigarette smoke in the present experiment. The overexpression of cyclin $\mathrm{E}$ and D1 in the lungs of rats exposed to cigarette smoke suggests a promotion of $S$ phase entry for cell proliferation.

In this study, only the decrease of RAR $\beta$ and increase of cyclin E and PCNA were dose-dependent with regard to cigarette smoke exposure, suggesting a potential relationship. These results indicate that cigarette smoke exposure plays a significant role in these alterations. Cyclin $\mathrm{E}$ levels determine the time point when cells enter $\mathrm{S}$ phase $[37,38]$. In addition, of the two cyclins measured in this study, only cyclin E was strongly associated with the concentration of retinoic acid and level of RAR $\beta$. Together, these data suggest that increased cell proliferation in response to increased expression of cyclin $E$ is associated with the decrease of RAR $\beta$ in lungs exposed to cigarette smoke. 


\section{Cyclin D1}

Unlike cyclin E, cyclin D-type cyclins are synthesized in early $G_{1}$ phase. Previous studies have reported an increase in cyclin D1 expression in non-small-cell lung cancer (NSCLC) cases [39]. cJun is reported to promote $\mathrm{G}_{1}$ phase progression through direct transcriptional control of cyclin D1 [40].

Our study suggested that, similar to RAR $\alpha$, cyclin D1 expression increased in a dose-dependent manner according to increasing cigarette smoke exposure; no significant increases were demonstrated in cyclin D1 levels until cigarette smoke exposure reached 3 packs/ d. Cyclin D1 levels measured across the treatment groups were inversely related to lung retinoic acid levels $(P<0.05)$. Cyclin D1 levels were also very strongly associated with cJun levels measured by Western Blot $(r=0.98, P<0.001)$. Together, these findings suggest that RAR $\alpha$, cJun, and cyclin D1 act in concert to promote cigarette smoke induced cell proliferation independently of RAR $\beta$.

\section{Role of RARy in lung cancer}

RAR $\gamma$ levels in the lung were shown to decrease in a dose-dependent fashion with increasing cigarette exposure (Fig. 2). RARY has been associated with elastin production [41], and its reduced expression appears to be associated with the development of emphysema [42]. Decreased RAR $\gamma$ has also been found to be depleted in $41 \%$ of non-small-cell lung cancer [43]. The precise role for RAR $\gamma$ in cigarette smoke-induced lung cancer needs further investigation.

\section{Conclusion}

Cigarette smoke-induced retinoic acid deficiency was found to be highly associated with multiple molecular biomarkers of increased lung cancer risk in this study. Increasing cigarette smoke exposure depleted lung retinoic acid and decreased RAR $\beta$ and RAR $\gamma$ expression in a dose-dependent fashion. The decreased RAR $\beta$ expression was associated with a dose-dependent increase in cyclin E and PCNA. The smoke exposure increased RAR $\alpha$ in a curvilinear fashion. This curvilinear response was also observed for cyclin D1 and cJun. Two independent signal cascades mediated by decreased RAR $\beta$ and increased RAR $\alpha$ expression may contribute to the precancerous lesions observed from our previous study [3]. Whether the transcription regulation in this model through epigenetics or transcription factor:DNA interactions as measured by a ChIP assay and whether the addition of dietary vitamin $\mathrm{A}$ in conjunction with cigarette smoke exposure prevents and/or decreases lung cancer risk are worth future exploration.

\section{Abbreviations}

CKI: Cyclin Kinase Inhibitor; HPLC: High Pressure Liquid Chromatography; NSLC: Non-Small Cell Lung Cancer; PCNA: Proliferating Cell Nuclear Antigen; RAR: Retinoic Acid Receptor.

\section{Competing interests}

The authors declare that they have no competing interests.

\section{Authors' contributions}

YX conducted all primary research, performed data analysis, and wrote manuscript. EH performed literature review, edited, and initially submitted the manuscript. WW and RB served as advisors for Yuan, and edited and approved the manuscript. All authors read and approved the final manuscript.

\section{Acknowledgements}

We thank Provost Stanton L. Jones and Dean Dorothy F. Chappell for their financial support enabling summer student research opportunities at Wheaton College. We are grateful for the skillful editing of Vickie A. Baybutt. Funding for research was provided by the Kansas Agricultural Experiment Station (contribution No. 06-210 J), and also by the Aldeen and Alumni Association Grants from Wheaton College with its motto "For Christ and His Kingdom".

Received: 27 July 2014 Accepted: 15 September 2015

Published online: 14 October 2015

\section{References}

1. U.S. Cancer Statistics, American Cancer Society. Cancer Facts and Figures-2014. Atlanta (GA): American Cancer Society. 2014;1:2-3.

2. Russell RM. Beta-carotene and lung cancer. Pure and Appl Chem. 2002;74:1461-57.

3. Li T, Molteni A, Latkovich P, Castellani W, Baybutt RC. Vitamin A Depletion Induced by Cigarette Smoke Is Associated With the Development of Emphysema in Rats. J Nutr. 2003;133:2629-34.

4. Sporn MB, Dunlop NM, Newton DL, Smith JM. Prevention of chemical carcinogenesis by vitamin $A$ and its synthetic analogs (retinoids). Fed Proc. 1976;35:1332-8.

5. Dogra SC, Khanduja KL, Gupta MP. The effect of vitamin A deficiency on the initiation and post-initiation phases of benzo(a)pyrene-induced lung tumorigenesis in rats. Br J Cancer. 1985;52:931-5.

6. Freemantle SJ, Spinella MJ, Dmitrovsky E. Retinoids in cancer therapy and chemoprevention: promise meets resistance. Oncogene. 2003;22:7305-15.

7. Tockman MS. Lung cancer: chemoprevention and intermediate effect markers. IARC Sci Publ. 2001;154:257-70.

8. Wang XD, Liu C, Bronson RT, Smith DE, Krinsky NI, Russell M. Retinoid signaling and activator protein-1 expression in ferrets given beta-carotene supplements and exposed to tobacco smoke. J Natl Cancer Inst. 1999;91:60-6.

9. Ross-Innes CS, Stark R, Holmes KA, Schmidt D, Spyrou C, Russell R, et al. Cooperative interaction between retinoic acid receptor-alpha and estrogen receptor in breast cancer. Genes Dev. 2010;24:171-82.

10. Myga-Nowak M, Pacholska-Bogalska J, Kwaśniewski W, Kwaśniewska A, Goździcka-Józefiak A. Proliferation of cells and expression of RARs, RXRs and HPV viral E6 and E7 proteins in cervical cancer cell lines after treatment with ATRA. Ann Agric Environ Med. 2011;18:145-50.

11. Verma AK, Shoemaker A, Simsiman R, Denning M, Zachman RD. Expression of retinoic acid nuclear receptors and tissue transglutaminase is altered in various tissues of rats fed a vitamin A-deficient diet. J Nutr. 1992;122:2144-52.

12. Sherr CJ. Cancer cell cycles. Science. 1996;274:1672-7.

13. Mechta-Grigoroiu F, Gerald D, Yaniv M. The Mammalian Jun proteins: redundancy and specificity. Oncogene. 2001;20:2378-89.

14. Tulchinsky E. Fos family members: regulation, structure and role in oncogenic transformations. Histol Histopathol. 2000;15:921-8.

15. Szabo E, Riffe ME, Steinberg SM, Birrer MJ, Linnoila RI. Altered cJUN expression: an early event in human lung carcinogenesis. Cancer Res. 1996;56:305-15.

16. Reeves PG, Nielsen FH, Fahey Jr GC. AIN-93 purified diets for laboratory rodents: final report of the American Institute of Nutrition ad hoc writing committee on the reformulation of the AIN-76A rodent diet. J Nutr. 1993;123:1939-51. 
17. Barua AB, Olson JA. Reversed-phase gradient high-performance liquid chromatographic procedure for simultaneous analysis of very polar to nonpolar retinoids, carotenoids and tocopherols in animal and plant samples. J Chromatog B. 1998;707:69-79.

18. Edes TE, Gysbers DS. Carcinogen-induced tissue vitamin A depletion. Potential protective advantages of beta-carotene. Ann NY Acad Sci. 1993;686:203-11.

19. Xue Y, Meadors EP, Wang W, Baybutt RC. Microarray analysis reveals that dietary retinoic acid may suppress cancer-related gene expression of the lungs of cigarette-smoked rats. J Nutr Food Sci. 2012;S2:1-6.

20. Heussen GA, Schefferlie GJ, Talsma MJ, vanTil H, Dohmen MJ, Brouwer A, et al. Effects on thyroid-hormone metabolism and depletion of lung vitamin $A$ in rats by airborne particulate matter. J Toxicol Environ Health. 1993:38:419-34.

21. Berard J, Laboune F, Mukuna M, Massa S, Kothary R, Bradley WE. Lung tumors in mice expressing an antisense RARbeta2 transgene. FASEB J. 1996;10:1091-7

22. Xu XC, Sozzi G, Lee JJ, Pastorino U, Pilotti S, Kurie JM, et al. Suppression of retinoic acid receptor $\beta$ in non-small-cell lung cancer in vivo: implications for lung cancer development. J Nat; Cancer Inst. 1997;89:624-9.

23. Inui N, Sasaki S, Suda T, Chida K, Nakanura H. The loss of retinoic acid receptor alpha, beta and alcohol dehydrogenase 3 expression in non-small cell lung cancer. Respirology. 2003;8:302-9.

24. Virmani AK, Rathi A, Zochbauer-Muller S, Sacchi N, Fukuyama Y, Bryant D, et al. Promoter methylation and silencing of the retinoic acid receptor-beta gene in lung carcinomas. J Natl Cancer Inst. 2000;92:1303-7.

25. Suh YA, Lee HY, Virmani A, Wong J, Mann KK, Miller WH, et al. Loss of retinoic acid receptor beta gene expression is linked to aberrant histone $\mathrm{H} 3$ acetylation in lung cancer cell lines. Cancer Res. 2002;62:3945-9.

26. Chen-ye Z, Yong-tang J, He-yun X, Hu Z, Zhang W, Xiao-yu S, et al. Relationship between promoter methylation of p16, DAPK and RAR beta genes and the clinical data of non-small cell lung cancer. Zhonghua Yixue Yichuanxue Zazhi. 2011;28:23-8.

27. Zochbauer-Muller S, Lam S, Toyooka S, Virmani AK, Toyooka K, Seidl S, et al. Aberrant methylation of multiple genes in the upper aerodigestive tract epithelium of heavy smokers. Int J Cancer. 2003;107:612-6.

28. Lotan R. Retinoids in cancer chemoprevention. FASEB J. 1996;10:1031-9.

29. Topletz AR, Tripathy S, Foti RS, Shimshoni JA, Nelson WL, Isoherranen N. Induction of CYP26A1 by metabolites of retinoic acid: Evidence that CYP26A is an important enzyme in the elimination of active retinoids. Molecul Pharmacol. 2015;87:430-41.

30. Wolbach SB, Howe PR. Tissue changes following deprivation of fat-soluble A vitamin. J Exp Med. 1925;42:753-77.

31. Huo L, Cui DM, Yang X, Gao ZY, Trier K, Zeng JW. All-trans retinoic acid modulates mitogen-activated protein kinase pathway activation in human scleral fibroblasts through retinoic acid receptor beta. Molecular Vision. 2013;19:1795-803.

32. Lin F, Xiao D, Kolluri SK, Zhang X. Unique anti-activator protein-1 activity of retinoic acid receptor beta. Cancer Res. 2000;60:3271-80.

33. Karin M, Liu Z, Zandi E. AP-1 function and regulation. Curr Opin Cell Biol. 1997;9:240-6.

34. Pfahl M. Nuclear receptor/AP-1 interaction. Endocr Rev. 1993;14:651-8.

35. Schule R, Rangarajan P, Yang N, Kliewer S, Ransone LJ, Bolado J, et al. Retinoic acid is a negative regulator of AP-1-responsive genes. Proc Natl Acad Sci U S A. 1991:88:6092-6.

36. Uray IP, Shen Q, Seo HS, Kim H, Lamph WW, Bissonnette RP, et al. Rexinoid-induced expression of IGFBP-6 requires RAR beta-dependent permissive cooperation of retinoid receptors and AP-1. J Biol Chem. 2009;284:345-53.

37. Dulic V, Lees E, Reed SI. Association of human cyclin E with a periodic G1-S phase protein kinase. Science. 1992;257:1958-61.

38. Porter PL, Malone KE, Heagerty PJ, Alexander GM, Gatti LA, Firpo EJ, et al. Expression of cell-cycle regulators p27Kip1 and cyclin E, alone and in combination, correlate with survival in young breast cancer patients. Nat Med. 1997:3:222-5.

39. Chen Y, Cao Y, Yang D, Li K, Wang Z, Zhu J, et al. Increase of the therapeutic effect on non-small-cell lung cancer cells with combination treatment of shRNA against Cyclin D1 and Bcl-xL in vitro. Exp Ther Med. 2012;3:255-60.

40. Wisdom R, Johnson RS, Moore C. c-Jun regulates cell cycle progression and apoptosis by distinct mechanisms. EMBO J. 1999;18:188-97.
41. McGowan S, Jackson SK, Jenkins-Moore M, Dai HH, Chambon P, Snyder JM Mice bearing deletions of retinoic acid receptors demonstrate reduced lung elastin and alveolar numbers. Am J Respir Cell Mol Biol. 2000;23:162-7.

42. Hind M, Corcoran J, Maden M. Pre and postnatal lung development, maturation, and plasticity - Temporal/spatial expression of retinoid binding proteins and RAR isoforms in the postnatal lung. Am J Physiol-Lung Cell Mol Physiol. 2002;282:L468-76.

43. Picard E, Seguin C, Monhoven N, Rochette-Egly C, Siat J, Borelly J, et al. Expression of retinoid receptors genes and proteins in non-small-cell lung cancer. J Natl Cancer Inst. 1999;91:59-66.

\section{Submit your next manuscript to BioMed Central and take full advantage of:}

- Convenient online submission

- Thorough peer review

- No space constraints or color figure charges

- Immediate publication on acceptance

- Inclusion in PubMed, CAS, Scopus and Google Scholar

- Research which is freely available for redistribution 